\title{
Leadership contingencies in the retention of women in higher education
}

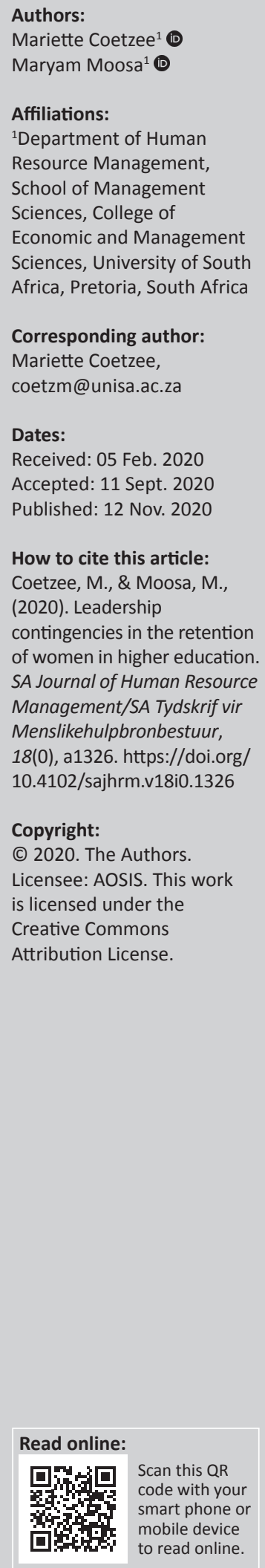

Orientation: Providing leadership opportunities and eliminating barriers to advance to or remain in leadership positions may influence the retention of women at academic institutions.

Research purpose: The purpose of this study was to determine the impact of leadership contingencies on the retention of women.

Motivation for the study: Women could be better equipped to succeed in leadership roles if more is known about the challenges they face to advance to or remain in leadership positions and how these challenges should be managed to ensure their retention.

Research approach/design and method: A quantitative research approach was followed in this study and a questionnaire was used to collect data. A non-probability simple random sample of 2000 female employees from an academic institution in South Africa was drawn and a total of 311 questionnaires were completed, with a response rate $15.6 \%$. Principal axis factor analysis with a Varimax rotation extracted six leadership contingency factors.

Main findings: The factor analysis identified six leadership contingencies that play a significant role in the retention of women in leadership positions: barriers to advancement, capabilities of women, acceptance of women as leaders, work-life balance, advancement opportunities and success beliefs. All of these factors were significantly related to retention factors, such as the fulfilment of unique needs, growth opportunities, recognition, pleasant work conditions, sound relationships and support.

Practical/managerial implications: This study contributes to a better understanding of the complexity in the career progression and retention of women in leadership positions.

Contribution/value-add: An understanding of challenges faced by women in leadership positions would enable organisations to implement retention strategies and allow institutions to capitalise on the value women could add to the management of academic institutions.

Keywords: retention; barriers to advancement; capabilities of women; work-life balance; advancement; success beliefs; leadership opportunities.

\section{Introduction}

Although the under-representation of women in top management positions is acknowledged, higher education institutions fail to make concerted efforts to retain women managers (Ramohai, 2019). The few women who succeed in breaking the glass ceiling do not survive for a long period in these positions. The severity of the problem has not yet been acknowledged, with the Department of Higher Education and Training failing to provide formal statistics to expose the depth of the problem. According to the Universities South Africa Forum (USAF, 2015), of the 26 public higher education institutions, only four have women as vice-chancellors. According to Kapareliotis and Miliopoulou (2019), women do not progress past the Assistant Professor level and the proportion of women decreases in higher hierarchy ranks (Salinas \& Bagni, 2017). South Africa's progress in reducing or eliminating unequal representation of women in top management positions has been almost stagnant despite the ideological and policy commitments to gender equality (Ramohai, 2019). Although the number of women entering the workforce has been continuously increasing, only a small number of them manage to advance to management levels. According to Scheepers, Douman and Moodley (2018), in South Africa, women occupy only $23 \%$ of positions involved in making economic decisions and only $4 \%$ of Chief Executive Officer positions. These statistics are only symptoms of a larger underlying disease where men are considered more worthy and valuable than women. The call by government to empower women has led to South African higher education institutions implementing programmes with the aim to capacitate women. However, the dissonance between such programmes and what 
happens in practice is visible in the institutional gender inequality that continues to exist.

Various studies have reported on the constraints faced by women who aspire to management positions. Lekchiri, Crowder, Schnerre and Eversole (2019) conducted a study at a tertiary institution in Morocco and identified the following gender bias behaviours: abusive, verbal or physical or sexual harassment; unfair treatment; dismissal; and a lack of trust, recognition and acknowledgement. The most common constraints identified by various other studies include the glass ceiling, gender discrimination, organisational culture, work and family conflict, old boys network, stereotyping, poor support and personal characteristics (April \& Sikatali, 2019; Cohen, Dalton, Holder-Webb, \& McMillan, 2018; Khalid \& Sekiguchi, 2019; Tabassum, Shafique, Konstantopoulou, \& Arslan, 2019). According to Shepered (2017), women within the South African higher education context experience marginalisation, under-representation and the glass ceiling as the major obstacles in their career progression.

Perhaps of greater concern to the field of human resource management is the high number of women managers leaving organisations today. According to Ramohai (2019), women often leave their jobs for non-economic reasons and opt out of senior academic positions or move to other tertiary institutions for satisfaction reasons. Satisfaction was mostly related to disgruntlements pertaining to institutional climate and practices. In line with the problems women encounter, Deery (2008) reported that emotional exhaustion has been identified as a major cause of turnover of women in management positions. According to Clark (2007), organisations are failing to retain women because of the organisation's inability to accommodate women's needs.

There is a good case to be made for including women as part of management. According to Willows and Van der Linde (2016), women's ability to improve the corporate governance quality and the addition of soft skills provide tangible and intangible benefits that could translate into improved company performance. The inclusion of women at management levels further stimulates and fosters creativity and innovation. Kengne (2016) also outlined the value women add to a business given their high monitoring skills and low-risk preferences. According to Groenewald, Odendaal and Bezuidenhout (2019), female representation in top management structures brings informational and social diversity benefits. South Africa is experiencing a state of crisis with regard to the availability of skilled or 'knowledge workers' (Kerr-Phillips \& Thomas, 2009). This fuels the problem, making it very difficult for organisations to replace talented employees, especially at management level. According to Boxall (2017), gender diverse companies are $15 \%$ more likely to outperform the national industry mean. Organisations are thus presented with an opportunity to capitalise on the contributions made by women should they invest in diversity management. According to
Scheepers et al. (2018), organisations could implement several talent management interventions to mitigate the challenges faced by women.

Cho and Huang (2012) confirmed the significance of professional advancement as a retention factor because the absence of growth prospects can leave employees feeling dissatisfied and ultimately result in them leaving the organisation. Ramohai (2019) supported this finding and stated that women resign or move to other institutions mostly because of a quest for growth. Not only have women been prevented from advancing beyond certain management levels (glass ceiling phenomena), but also their appointment in senior positions took place at a slower pace. In contrast, men are appointed in leadership positions at an astounding pace (glass escalator phenomena) (Jauhar \& Lau, 2018).

Women form an essential part of any workforce because they bring with them a wealth of experience and knowledge. Jauhar and Lau (2018) shared this viewpoint and see the promotion of women not only as an equity initiative but also as a necessity for sustainable national development. According to Willows and Van der Linde (2016), women are a source of brainpower that should be utilised to gain a competitive advantage. Organisations would, therefore, lose out on a valuable resource if the retention and advancement of women is not managed as a priority. According to Zhong, Blum and Couch (2018), work is only a fragment of a woman's multiple roles, of which the traditional role involved looking after the family. With the dual roles that women fulfil in the home and work spheres, they are however in desperate need of assistance to help them balance work and life. If organisations could implement strategies to assist women to balance work and life, they could retain women as a key resource.

The world of work is changing and transforming continuously and one of the most important contributing factors to this is the role of women in the workplace. In South Africa, the current rate of labour force participation of women is at $46.7 \%$ (down from $51.4 \%$ in 2016) (SA Department of Labour, 2016). Women forming such a large portion of the workforce inevitably emphasises the need for organisations to implement work policies and practices that would cater for their needs.

\section{Women in leadership positions}

Women are not only entering the workforce but also emerging as leaders in their chosen fields (Cubillo \& Brown, 2003). Although the number of women in management and senior level positions has increased from $26 \%$ to $29 \%$, this representation is dismal considering the fact that women make up nearly half of the workforce (Vallie, 2018). It seems as if South Africa is still struggling to accept the notion of a woman doing a man's job - hence the intrinsic biases held by both men and women about women in top positions. Currently, there are no female CEOs running any of South Africa's 40 largest listed companies and women make up only one-fifth of the 
directors who serve on the boards of companies listed on the Johannesburg Stock Exchange (Mans-Kemp, 2019). After decades of being disadvantaged and ignored, women are gradually breaking barriers to make their mark in the world of work. Although women are entering the realm of management, this is taking place at a very slow pace. The poor representation of women in management positions is evident of a change in policy but not reform. Hoobler, Lemmon and Wayne (2011) recognised that there are many obstacles to overcome before women would be equitably represented in leadership positions. Women's voyage into senior management, which previously was a male-dominated arena, has been far too slow and not on par with expectations, with the added pressure and prevalence of the gender pay gap (Bosch, 2015). This indicates that women are achieving success, but not at the same pace as men, nor as fast as anticipated.

\section{Obstacles faced by women who wish to advance to leadership positions}

Compounding the problem of poor representation in leadership positions, women still are being paid less than their male counterparts (Zhong et al., 2018). According to a report by Price Waterhouse Coopers, $61 \%$ of women are remunerated below the median, whilst $63 \%$ of men are remunerated above the median (https:/ /ewn.co.za/2018/08/16/survey-womenrepresent-only-20-of-senior-management-in-sa. Accessed on 21 November 2019).

One of the outcomes of women's lack of advancement is the notorious 'glass ceiling'. Jauhar and Lau (2018) defined the glass ceiling as an invisible barrier that hinders women from advancing beyond certain levels to reach top management positions in organisations. Related to the barriers preventing women from advancing beyond a certain level, the golden skirts syndrome refers to a situation in which only a few well-connected women are selected to serve on multiple boards (Mans-Kemp, 2019). Adding to the dilemma of gender inequality is the presence of the queen-bee syndrome. Women who manage to advance to management positions are often responsible for the hindrance in the career progression of other women (April \& Sikatali, 2019).

Another phenomenon that is affecting women in the workplace is the presence of the 'glass cliff'. Women who break through the glass ceiling often end up on a glass cliff, where the glass cliff represents being appointed into precarious leadership positions in which they are doomed to fail (Javadi et al., 2016). The glass cliff is also associated with sexism in the workplace (Ryan, Haslam, \& Postmes, 2007). Women who make it into leadership positions will have to work exceptionally hard to prove their competence or succumb to the pressure of these challenges.

The multiple roles expected of women have put the spotlight on the importance of women being able to maintain a balance between work and life. The majority of households in South Africa are run by single mothers (Statistics South Africa, 2017). The new egalitarian gender roles have now put the spotlight on equality, whereby men are no longer the only breadwinners and women are no longer primarily responsible for the household (Sweeting, Bhaskar, Benzeval, Propham, \& Hunt, 2014). Unless a mindset change on the role of women in the workplace is made, at home and in society at large, inequality will continue to exist in the workplace.

Greenhaus, Ziegert and Allen (2012) opined that organisations can help improve the work-life balance and diminish workfamily conflict by supporting work-life balance initiatives. According to the Top Employers Institute, 94\% of certified employers in South Africa report having specific diversity initiatives in place to help women progress into senior management. These initiatives include working flexitime $(64 \%)$, compressed working hours $(26 \%)$ and on-site crèche and nursing room facilities (25\%) (Boxall, 2017).

There are many challenges facing women managers of the 21st century. According to Ramohai and Marumo (2016), these challenges are mostly attributed to power struggles that aim to subdue women to lower positions and create spaces for men in senior positions. Gender narratives often paint women as being less effective, possessing unsavoury leadership styles and lacking leadership qualities (Burkinshaw \& White, 2017). The challenges that women face can be separated into either 'push' or 'pull' factors. Push factors force women out of the organisation and include issues such as gender discrimination, lack of support, lack of advancement opportunities, domination, biases and abuse. Pull factors entice a woman away from her job and include issues such as family and children responsibilities. In a study by Kirai and Mukulu (2012), the three most common challenges faced by women included gender discrimination (25\%), work-life balance (30\%) and a lack of support by the organisation (24\%). Other challenges included lack of support by family, lack of selfconfidence and inefficient systems in the workplace. Women indicated that they dealt with these challenges by working harder $(15 \%)$, attempting to balance work and family responsibilities (12\%) and ignoring detractors (13\%) (Kirai \& Mukulu, 2012). Women also indicated that perseverance, focusing on priorities, consulting widely and seeking support were critical in assisting them to succeed in their leadership positions. According to Mayer and May (2018), women leaders often experience thoughts and feelings of exclusion, marginalisation, voicelessness and a lack of authority.

Considering the numerous obstacles that women have to face in pursuing leadership positions, it is not surprising that such a low percentage of women manage to advance to and stay in leadership positions.

\section{Retention}

It is not only the appointment of women as leaders that creates reason for concern but also the ability of organisations to retain the services of these women. Leadership opportunities signify the prospect of employees being given the chance to advance in their careers, possibly into leadership positions. It denotes evolution and development as critical underlying concepts. 
Factors such as career opportunities, training and development, employee well-being, promotion and opportunities for growth have all been highlighted as key retention factors (Das \& Baruah, 2013; Döckel, 2003; Veldsman, 2003). Each of these factors, in turn, embraces the same fundamental concept of growth, which is the major driver of leadership opportunities as a retention factor. Employee retention is thus highly related to growth, advancement and development.

From an overall retention perspective, six fundamental factors were identified as central to employee retention, as illustrated in Figure 1 (Döckel, Basson, \& Coetzee, 2006). With reference to the retention of women, four of the six retention factors are directly related to leadership contingencies, namely, the training and development of women, support provided to women, opportunities afforded to women to advance their careers and assisting women to lead a balanced work and life.

\section{Research design}

A quantitative research design was chosen for this study. The study used a cross-sectional, descriptive and exploratory research design in order to determine leadership contingencies and to determine the relationship between leadership contingencies and retention. A cross-sectional research design provided a general viewpoint on the research topic at the time when the study was conducted by surveying a selection of respondents with regard to a list of variables (Kumar, 2014; Welman, Kruger, \& Mitchell, 2005). The descriptive analysis did not aim to draw conclusions on causality, but instead attempted to explore a specific situation at a specific point in

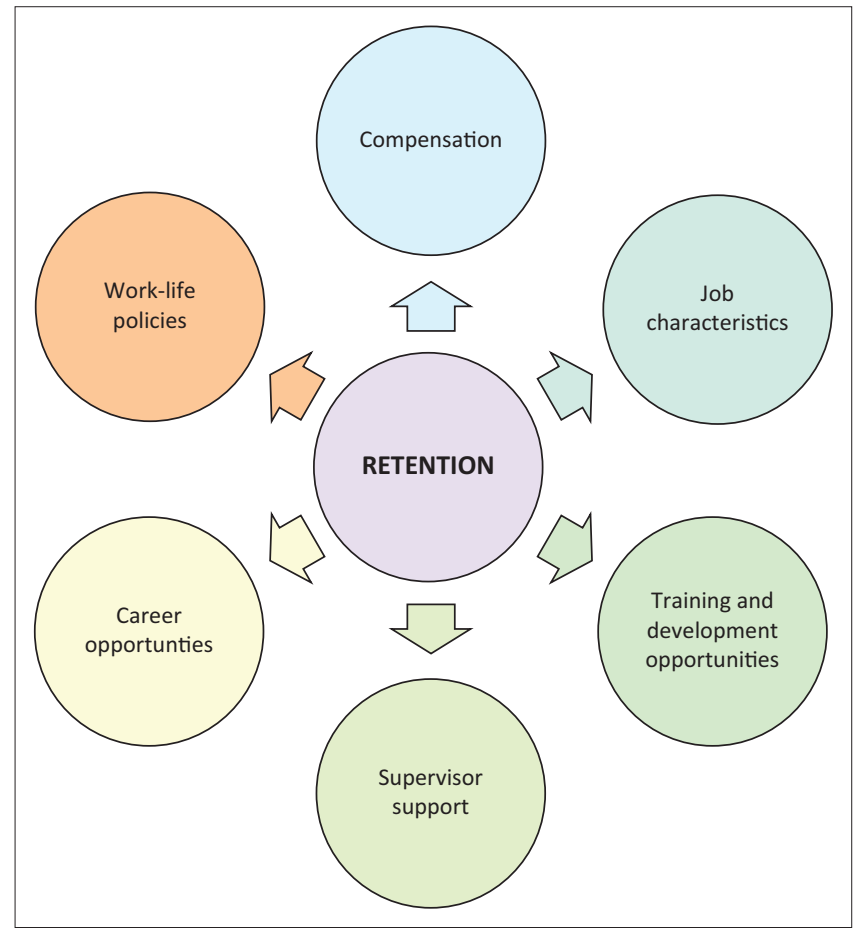

Source: Adapted from Döckel, A. (2003). The effect of retention factors on organisational commitment: An investigation of high technology employees. Unpublished MCom dissertation (Human Resource Management). University of Pretoria, Pretoria

FIGURE 1: Retentionfactors. time (Leedy \& Ormrod, 2005; Welman et al., 2005). Exploratory research was conducted to investigate the research questions without providing binding or conclusive solutions to existing problems (Terre Blanche, Durrheim, \& Painter, 2006).

\section{Research method}

The type of data required largely determines the most appropriate method to be used. In line with the quantitative approach, a survey research method, which is particularly suitable for investigating a potential relationship between two or more variables, was chosen. After a careful review of the literature on the topics of retention and leadership, it was found that no suitable questionnaire existed to address the aims of this study. An instrument was thus developed to determine leadership constructs and the relationship between leadership and retention of women within the higher education context in South Africa.

\section{Population and sampling}

The study population consisted of 2732 female employees from an academic institution in South Africa. A nonprobability simple random sample of 2000 female employees was drawn. A total of 311 web-based questionnaires were completed, which resulted in a response rate of $15.6 \%$. A list of all permanent female employees, categorised according to certain demographics, was obtained from the human resource department at the institution.

\section{Measuring instrument}

A questionnaire was developed to measure women's perceptions of and beliefs about leadership opportunities and how it affected their decisions to remain in the employment of the university. Perceptions and beliefs were measured by means of a six-point Likert interval scale. The statistics that were used for interval data included the mean (average score for a group), frequencies, standard deviation and Pearson's product moment correlation.

\section{Research procedure}

After the research aims were formulated, the sample was determined. A web-based questionnaire was developed and submitted to a statistician for comments. A pre-test (pilot run) was performed to ensure that the questionnaire met the study's expectations in terms of the information that had to be obtained. After ethical clearance was obtained, the survey link was e-mailed to the participants. All completed responses were automatically captured and downloaded into Microsoft Excel, to be used for statistical analysis using the Statistical Package for Social Sciences (SPSS), version 22.0.

\section{Statistical analysis}

Descriptive and inferential statistics were used to analyse the data. Correlation and multiple regression were used to determine the relationship between leadership factors and retention. 
TABLE 1: Leadership and retention factors: Descriptives and Cronbach's alpha.

\begin{tabular}{lccccc}
\hline Construct & Mean & $\begin{array}{c}\text { Standard } \\
\text { deviation }\end{array}$ & Skewness & Kurtosis & $\begin{array}{c}\text { Cronbach's } \\
\text { alpha }\end{array}$ \\
\hline Leadership contingencies & & & & & \\
Barriers & 3.81 & 1.32 & -0.20 & -0.98 & 0.87 \\
Capabilities & 4.81 & 0.79 & -0.59 & 0.45 & 0.61 \\
Acceptance & 4.26 & 1.09 & -0.51 & -0.03 & 0.74 \\
Work-life balance & 3.30 & 0.94 & 0.12 & -0.03 & 0.70 \\
Advancement & 4.20 & 0.91 & -0.54 & 0.01 & 0.77 \\
Success beliefs & 4.08 & 1.12 & -0.45 & -0.19 & 0.67 \\
Retention & & & & & \\
Unique needs & 3.87 & 1.07 & -0.34 & -0.56 & 0.79 \\
Growth & 4.28 & 1.18 & -0.95 & 0.62 & 0.82 \\
Recognition & 4.28 & 1.13 & -0.91 & 0.81 & 0.88 \\
Work conditions & 3.29 & 0.97 & 0.25 & -0.43 & 0.70 \\
Relationships & 2.84 & 1.17 & 0.54 & -0.37 & 0.77 \\
Support & 3.53 & 1.37 & 0.12 & -0.97 & 0.83 \\
\hline
\end{tabular}

A principal factor analysis was performed to identify leadership contingencies and retention factors. Once the Kaiser-Meyer-Olkin and Bartlett's test values had been determined, the analysis identified the number of factors to be extracted by means of eigenvalues. The Kaiser criterion was used for the purpose of factor extraction. This study used Varimax rotation to determine the factor matrix. All factor loadings greater than or equal to 0.30 were considered significant. Cronbach's alpha coefficients and inter-item correlation coefficients were used to assess the internal consistency of the questionnaire. The Cronbach's alpha coefficients were above $60 \%$ for all the factors identified, thus indicating that all the items measured the same attribute. All factors obtained Cronbach's alpha coefficients ranging from 0.61 to 0.87 without any items being deleted. Descriptive statistics (e.g. mean, standard deviation, skewness and kurtosis) were used to analyse the distribution of the values of each item included in the various factors. After the number of factors and the total variance were determined, the factor loadings in the pattern matrix were analysed and the factors were labelled. Table 1 provides descriptive statistics and the results of the reliability analysis.

\section{Ethical consideration}

Ethical approval to conduct the study was obtained from the Department of Human Resource Management at the University of South Africa (Ethical clearance number: 2015_RPSC_092).

\section{Results}

Significant relationships existed between barriers to advancement and each of the retention variables (unique needs, growth, recognition, work conditions and relationships). Work conditions ( $r=0.26 ; p=0.00$; small practical effect) and relationships $(r=0.19 ; p=0.00$; small practical effect $)$ provided positive correlations, whilst recognition $(r=-0.38 ; p=0.00$; medium practical effect), growth $(r=-0.25 ; p=0.00$; small practical effect) and unique needs $(r=-0.22 ; p=0.00$; small practical effect) provided negative correlations.
Capabilities seemed to be the exception, with only one significant positive relationship found with work conditions $(r=0.23 ; p=0.00 ;$ small practical effect). No significant relationship existed between capabilities and any of the other retention variables (unique needs, growth, recognition, relationships and support). In terms of this study, the high mean score obtained for this factor (capabilities: $M=4.81$ ) shows that women believe in their capabilities and want to succeed in their careers.

Significant relationships existed between acceptance of women and the retention variables. The strongest positive relationship was with work conditions $(r=0.33 ; p=0.00$; medium practical effect), followed by support $(r=0.24 ; p=0.00$; small practical effect) and relationships $(r=0.23 ; p=0.00$; small practical effect). Recognition $(r=-0.37 ; p=0.00$; medium practical effect) had the strongest negative correlation with acceptance, trailed by unique needs and growth $(r=-0.27 ; p=0.00$; small practical effect).

The retention variables were significantly related to work-life balance, except for growth, where no significant relationship existed. Support $(r=0.37 ; p=0.00$; medium practical effect) had the strongest positive relationship with work-life balance, followed by relationships $(r=0.23$; $p=0.00$; small practical effect) and work conditions $(r=0.22 ; p=0.00$; small practical effect). Unique needs $(r=-0.24 ; p=0.00$; small practical effect) had the strongest negative correlation, whilst recognition ( $r=-0.14 ; p=0.01$; small practical effect) had the weakest negative correlation.

Advancement opportunities showed strong significant relationships with all the retention variables, with differences in the direction of the relationships. Recognition $(r=0.61$; $p=0.00$; large practical effect), unique needs $(r=0.59$; $p=0.00$; large practical effect $)$ and growth $(r=0.59 ; p=0.00$; large practical effect) showed strong positive relationships, whilst relationships $(r=-0.37 ; p=0.00$; medium practical effect) displayed the strongest negative correlation with advancement, followed by work conditions $(r=-0.32 ; p=0.00$; medium practical effect $)$ and support $(r=-0.28 ; p=0.00$; small practical effect). Women believe that they are provided with advancement opportunities, as indicated by the high mean score obtained for the advancement factor $(M=4.20)$.

Success beliefs were significantly related to all of the retention variables. Once again, positive and negative correlations were present. There were strong negative correlations between success beliefs and work conditions ( $r=-0.37 ; p=0.00 ;$ medium practical effect), relationships $(r=-0.33 ; p=0.00 ;$ medium practical effect $)$ and support $(r=-0.18 ; p=0.00$; small practical effect). On the other hand, success beliefs showed a strong positive relationship with recognition $(r=0.49 ; p=0.00$; medium practical effect), growth $(r=0.45 ; p=0.00$; medium practical effect) and unique needs $(r=0.36 ; p=0.00$; medium practical effect). According to the mean score obtained for success beliefs $(M=4.08)$, women believe that self-belief is critical to advancement. 
Regarding the relationship between leadership opportunities and retention, Table 2 illustrates how various leadership opportunities and beliefs are linked to retention factors such as unique needs, growth, recognition, work conditions, relationships and support.

\section{Regression analysis for leadership opportunities}

Six separate standard multiple regression analysis models were calculated, one model for each of the six dependent variables of retention (unique needs, growth, recognition, work conditions, relationships and support). The results are shown in Table 3.

\section{Unique needs}

The regression of the leadership variables on unique needs indicated a statistically significant result $(F=28.12 ; p \leq 0.01)$, accounting for $34 \%$ (adjusted $R^{2}=0.34$; large practical effect) of the variance in unique needs. The only leadership contingency that indicated a statistically significant relationship with unique needs was advancement $(\beta=0.52 ; p=0.00)$.

\section{Growth}

The regression of the leadership variables on growth indicated a statistically significant result $(F=41.66 ; p \leq 0.01)$, accounting for $44 \%$ (adjusted $R^{2}=0.44$; large practical effect) of the variance in growth. Work-life balance $(\beta=0.24$; $p=0.00)$, advancement $(\beta=0.56 ; p=0.00)$ and success beliefs $(\beta=0.29 ; p=0.00)$ were statistically significant predictors of growth.

\section{Recognition}

The regression of leadership variables on recognition indicated a statistically significant result $(F=48.25 ; p \leq 0.01)$, accounting for a high $48 \%$ (adjusted $R^{2}=0.48$; large practical effect) of the variance in recognition. Barriers $(\beta=-0.10$; $p=0.05)$, acceptance $(\beta=-0.12 ; p=0.02)$, work-life balance $(\beta=0.20 ; p=0.00)$, advancement $(\beta=0.51 ; p=0.00)$ and success beliefs $(\beta=0.24 ; p=0.00)$ indicated a statistically significant relationship.

\section{Work conditions}

The regression of leadership variables on work conditions indicated a statistically significant result $(F=15.17 ; p \leq 0.01)$, accounting for $22 \%$ (adjusted $R^{2}=0.22$; moderate practical effect) of the variance in work conditions. Capabilities $(\beta=0.22 ; p=0.00)$, advancement $(\beta=-0.22 ; p=0.00)$ and success beliefs $(\beta=-0.18 ; p=0.00)$ were statistically significant predictors of work conditions.

\section{Relationships}

The regression of leadership variables on relationships produced a statistically significant result $(F=11.53 ; p \leq 0.01)$, accounting for $17 \%$ (adjusted $R^{2}=0.17$; moderate practical effect) of the variance in relationships. Of the leadership constructs, advancement $(\beta=-0.29 ; p=0.00)$ and success beliefs $(\beta=-0.17 ; p=0.01)$ indicated a statistically significant

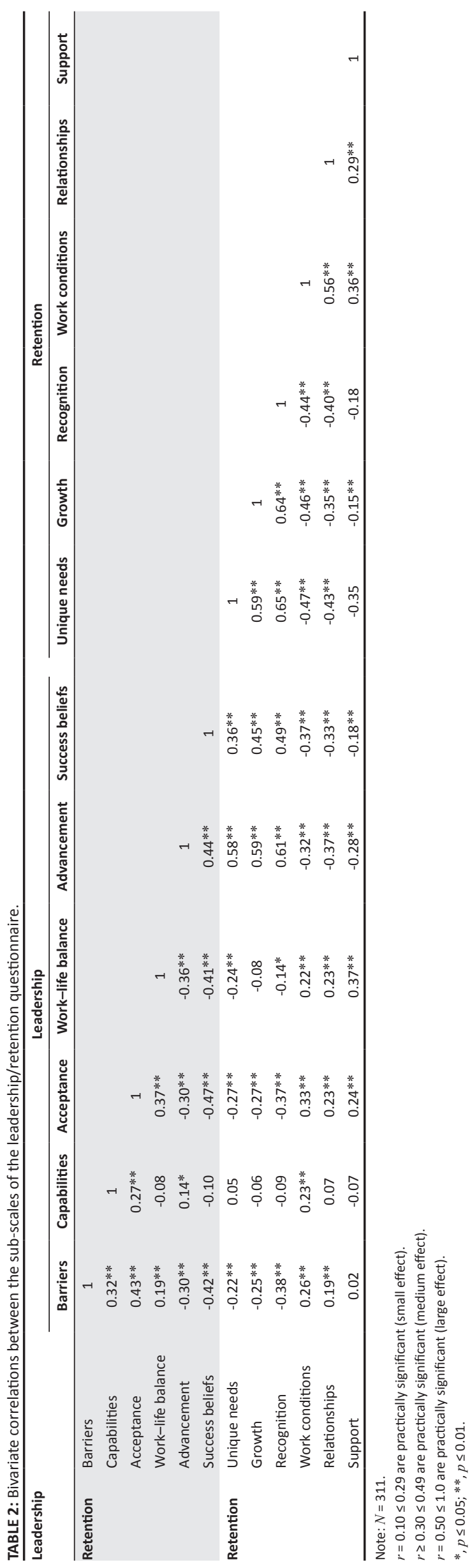


TABLE 3: Regression results for leadership contingencies and retention.

\begin{tabular}{|c|c|c|c|c|c|c|}
\hline \multirow{2}{*}{$\begin{array}{l}\text { Independent variables } \\
\text { (leadership opportunities) }\end{array}$} & \multicolumn{6}{|c|}{ Dependent variables (retention) } \\
\hline & Unique needs & Growth & Recognition & Work conditions & Relationships & Support \\
\hline Barriers & 0.00 & 0.50 & $-0.10 *$ & -0.01 & -0.02 & $-0.13^{*}$ \\
\hline Capabilities & 0.01 & -0.09 & -0.05 & $0.22 * *$ & 0.09 & -0.01 \\
\hline Acceptance & -0.07 & -0.05 & $-0.12 *$ & 0.10 & 0.03 & $0.16 *$ \\
\hline Work-life balance & 0.02 & $0.24 * *$ & $0.20 * *$ & 0.05 & 0.06 & $0.29 * *$ \\
\hline Advancement & $0.52 * *$ & $0.56 * *$ & $0.51 * *$ & $-0.22 * *$ & $-0.29 * *$ & $-0.18 * *$ \\
\hline Success beliefs & 0.11 & $0.29 * *$ & $0.24 * *$ & $-0.18 * *$ & $-0.17 *$ & 0.04 \\
\hline Adjusted $R^{2}$ & $0.34+++$ & $0.44+++$ & $0.48+++$ & $0.22++$ & $0.17++$ & $0.17++$ \\
\hline$F$ (p-value) & $28.12(0.00)$ & $41.66(0.00)$ & $48.25(0.00)$ & $15.17(0.00)$ & $11.53(0.00)$ & $11.78(0.00)$ \\
\hline
\end{tabular}

Note: Standardised beta coefficients are presented.

$*, p \leq 0.05 ; * *, p \leq 0.01 ; R^{2} \leq 0.12$ (small practical effect size).

,$++ R^{2} \geq 0.13 \leq 0.25$ (moderate practical effect size);,$+++ R^{2} \geq 0.26$ (large practical effect size)

relationship, with advancement as the highest significant predictor of relationships.

\section{Support}

The regression of leadership variables on support indicated a statistically significant result $(F=11.78 ; p \leq 0.01)$, accounting for $17 \%$ (adjusted $R^{2}=0.19$; moderate practical effect) of the variance in support. Barriers $(\beta=-0.13 ; p=0.03)$, acceptance $(\beta=0.16 ; p=0.01)$, work-life balance $(\beta=0.29 ; p=0.00)$ and advancement $(\beta=-0.18 ; p=0.00)$ indicated a statistically significant relationship and acted as a predictor of support.

\section{Discussion \\ Outline of the results}

The objective of this study was to determine the relationship between leadership contingencies and the retention of women.

Three leadership factors - barriers to advancement, acceptance and advancement opportunities - are intricately linked to the challenges that women face in advancing their careers or remaining in top leadership positions. The 'glass ceiling', 'glass cliff', leaking pipeline and 'old boys' phenomena represent the most common barriers to advancement (Kapareliotis \& Miliopoulou, 2019). Further obstacles in women's path to advance include gender stereotypes (Lips, 2013) and the gender pay gap (Bishu \& Alkadry, 2016), the lack of acknowledgement by male colleagues or managers (Kalaitzi, Czabanowska, Fowler-Davis, \& Brand, 2017), the importance assigned to institutional beliefs, which deny women the approval they deserve (acceptance) and the absence of development opportunities (advancement) (Thompson, 2015).

Women participants in this study expressed the difficulties they face in gaining recognition as experienced and qualified individuals. The women, however, reported favourably regarding the opportunities provided to take up leadership roles.

The leadership factors - capabilities, success beliefs and work-life balance - were also identified as key factors in enabling women to advance to leadership positions. Women have been working hard to level the playing field by obtaining more experience and improving their educational qualifications. This indicates that women have the capabilities required to succeed in leadership positions. In terms of this study, the high mean score obtained for this factor (capabilities: $M=4.81$ ) shows that women believe that capabilities play a significant role in career advancement.

Closely linked to capabilities is women's self-belief with regard to their leadership abilities. Women of the 21st century are slowly breaking down barriers and using their self-belief to achieve their goals. This incorporates the factor of success beliefs, which shows that women have strong beliefs in their capability to thrive and triumph against all odds. Women in middle management often do not put themselves forward for promotion because of a lack of self-confidence. These women underestimate their own abilities and are threatened by the 'imposter syndrome', which is a concept describing highachieving individuals who are unable to internalise their accomplishments and are filled with an irrational fear of not being able to live up to expectations (Boxall, 2017). According to Tabassum et al. (2019), resilience and the ability to adapt to adversity are directly related to women managers' career progression.

Work-life balance involves assisting women to maintain a balance between work and life so that they could take up leadership roles. This is one of the key topics of the new world of work and many organisations are trying to incorporate policies and procedures that support a more effective balance between work and life (Barber, Grawitch, \& Maloney, 2016). Work-life balance is an important factor in being able to reach leadership positions or availing oneself of leadership opportunities. Many women struggle with balancing the needs of work with the needs of the family, given the fact that the majority of women (52.4\%) have one or more children below the age of 18 years, and an astounding $65.9 \%$ of women are the main contributors to the household in terms of income (Statistics South Africa, 2019). These women would thus require an effective strategy to balance work and life or to reduce work-life conflict because they have work, household and childcare responsibilities. An overall majority (79.1\%) of women indicated that achieving a work-life balance was critical in managing a career (Boxall, 2017). 
The results indicated that there was a direct relationship between leadership contingencies and the retention of women. The given discussion explains how leadership relates to each of the retention factors.

\section{Barriers}

Barriers such as stereotyping, bias, lack of role models, poor growth opportunities and the glass ceiling prevent women from advancing to leadership positions and imply unfavourable working conditions that could have a direct impact on women's retention (April \& Sikatali, 2019).

\section{Capabilities}

The relationship between capabilities and retention of women implies that the more capable women are in terms of being successful managers, the more likely it would be that their male colleagues might meet them with resistance. This could be because of male managers feeling intimidated by the capabilities of their female colleagues and ultimately making their working conditions unpleasant. According to Ramohai (2019), women have to work extra hard to prove their worthiness. The belief that women cannot compete on equal footing with men emanates from a system of deep-rooted patriarchy that elevates the role of men over that of women.

\section{Acceptance}

The challenges experienced by women in gaining acceptance from their male counterparts strongly influence their preparedness to take up leadership roles. If women struggle with being accepted in leadership positions in the workplace, relationships will suffer and they will not be given the support they require from the organisation. The acceptance of women as leaders thus acknowledges their expertise, and provides them with opportunities to grow, which have a direct impact on their retention. According to Lekchiri et al. (2019), the lack of recognition and acknowledgement has serious implications for women managers' self-esteem, stress levels, frustration, productivity and ultimately retention.

\section{Work-life balance}

The more work-life conflict women experience, the more likely it is that these women would experience work conditions as non-supportive. Conflict and other negative consequences, such as stress, low-quality work or poor working relationships and work-family conflict, would make it impossible for women to remain in a leadership position (Harcar, 2007). Various studies have confirmed the importance of work-life balance in enabling women to succeed as managers (April \& Sikatali, 2019; Groenewald et al., 2019; Kirai \& Mukulu, 2012).

\section{Advancement opportunities}

When women are given advancement opportunities in the form of assuming leadership roles and are afforded further growth opportunities, they will perceive that their skills and abilities are being appreciated and their unique needs as women are fulfilled. These women will thus be more receptive to growth and development opportunities and, in return, will remain loyal to the organisation. According to Ramohai (2019), two professional reasons are responsible for women opting out of management positions, namely, growth prospects and power dynamics within institutions. Failure by institutions to capacitate women by creating growth opportunities raises questions about the value and worth institutions ascribe to women.

\section{Success beliefs}

When women hold a strong conviction in their propensity for success in terms of reaching leadership positions, it instils confidence in them as being competent. Confidence and selfefficacy play a significant role in persuading others to trust them and to invest in their expertise as leaders. Women who see a future for themselves in an organisation are likely to remain with the organisation. Kapareliotis and Miliopoulou (2019) emphasised the role women play in understanding their potential, embracing critical assessments and making an effort to reflect on their capabilities and objectives. Doubts about one's ability to be successful will have an impact on an individual's internal attributions and can lead to a decreased self-esteem, a warped self-concept and increased levels of stress and anxiety (Lekchiri et al., 2019).

The multiple regression analysis revealed the following relationships between leadership and retention.

\section{Unique needs}

A positive relationship exists between advancement and unique needs. This means that if women have the opportunity to advance, it will address one of their most important unique needs and likely contribute to their retention.

\section{Growth}

A positive relationship exists between growth and leadership, which implies that if organisations provide stimulating work and development opportunities to women, this would increase their retention as managers.

\section{Recognition}

The results indicate that advancement is the highest predictor of recognition. A negative relationship exists between recognition and leadership, given the presence of barriers and lack of acceptance by male colleagues. This finding suggests that when organisations recognise women and are committed to their advancement, women are likely to experience fewer barriers to reach leadership positions and greater acceptance by their male colleagues and superiors. Recognition and acknowledgement are also related to women's belief in their own success and contribute positively towards their retention.

\section{Work conditions}

Advancement and success beliefs indicated a negative relationship with work conditions. This means that when women consider work conditions as poor, they would not be given chances to advance and would question their conviction of being able to succeed in reaching a higher position. On the 
other hand, capabilities indicated a positive relationship as a predictor of work conditions, which implies that if women perceive that they are considered incapable of reaching leadership positions, they would perceive work conditions as poor and consider quitting their jobs.

\section{Relationships}

Relationships with one's supervisor are severely affected when organisations do not afford women advancement opportunities and when they begin to lose confidence in their ability to succeed in leadership positions. If women are denied the option to advance in their careers, it undeniably causes tension in the supervisor-subordinate relationship. This, in turn, could hamper retention efforts made by the organisation.

\section{Support}

When women are accepted by their male counterparts and able to balance work and family responsibilities effectively, it is likely that organisations would support them in meeting work demands and managing their time. Alternatively, a negative relationship exists between barriers and advancement when support is taken into consideration. This means that less support would be offered by the organisation if there are barriers hindering women's progress into leadership positions and if there are no advancement opportunities available for them to pursue.

\section{Practical implications}

Although organisations can embark on a number of interventions to facilitate the advancement of women into leadership positions, strategies to retain women as leaders are also required. According to Zhong et al. (2018), women should, however, take responsibility for their own advancement and can do that by making personal sacrifices, extending their job knowledge as far as possible, improving their educational qualifications and securing the support of their families. A key to career advancement is women's preparedness to work hard, engage in networking and build sound interpersonal relationships. On the other hand, organisations should be aware of constraints that make it impossible for women to succeed in leadership roles. Constraints such as the low credibility of women as leaders, family responsibility conflicts, non-supportive work environments, inequity in human resource practices (e.g. pay, promotion, training and wellbeing), biases and resistance/sabotage by male colleagues should be managed (Zhong et al., 2018). According to Scheepers et al. (2018), sponsorships should be considered as a strategy to advance talent management. Sponsorships involve a powerful, influential person pledging public support to an individual groomed for a leadership position. This will prevent women from becoming designated failures because of the glass cliff phenomenon.

With regard to tertiary institutions, Kapareliotis and Miliopoulou (2019) identified various strategies to eliminate institutional inequality. The pay gap in academia causes a vicious circle in which women often have to support the spouse who makes more money and thus end up sacrificing their careers. In addition, women are often identified as outsiders because public exposure and publications mostly apply to men, indicating that seniority, achievement and contributions are implicitly attributed to men. The absence of female symbolic representations should thus be addressed. The allocation of work can also send out a message of inequality when research activities are allocated to men whilst teaching activities are allocated to women. Tabassum et al. (2019) recommended the implementation of mentorship or coaching programmes, establishing networks and support groups for women, providing role models and offering workshops to equip women with skills necessary to cope with the challenges of a leadership position.

\section{Limitations of the study}

This study was conducted at a higher distance education institution and may not apply to organisations in other fields of practice or residential higher education institutions.

The sample of this study was relatively small and was considered slightly biased because of the high representation of white respondents in comparison with black respondents in the sample. The findings of the study may, therefore, be more applicable to white women between the ages of 36 and 45 years who work in the academic field.

\section{Conclusion}

This study identified six categories of leadership contingencies that have an impact on the retention of women: barriers to advancement, capabilities of women, acceptance of women, work-life balance, advancement opportunities and women's success beliefs. Leadership roles are important to women, and when leadership opportunities are not provided or barriers are not removed, the retention of women managers becomes problematic. This study supported previous research findings in that the retention of women managers is dependent on various factors and organisations need to make a concerted effort to eliminate gender inequality. Policies alone do not guarantee gender equality. Non-contextual factors such as attitudes and organisational culture towards women should also be transformed to facilitate the advancement and retention of women as leaders.

\section{Acknowledgements Competing interests}

The authors have declared that no competing interest exists.

\section{Author's contributions}

All authors contributed equally to this work.

\section{Funding information}

This research received a grant from the Masters and Doctoral Support Programme (MDSP), offered by Unisa to its academic staff. 


\section{Data availability statement}

Data sharing is not applicable to this article as no new data were created or analysed in this study.

\section{Disclaimer}

The views and opinions expressed in this article are those of the authors and do not necessarily reflect the official policy or position of any affiliated agency of the authors.

\section{References}

April, K., \& Sikatali, N. (2019). Personal and interpersonal assertiveness of female leaders in skilled technical roles. Effective Executive, XXII(4), 33-58.

Barber, L.K., Grawitch, M.J., \& Maloney, P.W. (2016). Work-life balance: Contemporary perspectives. In M.J. Grawitch \& D.W. Ballard (Eds.), The psychologically healthy workplace: Building a win-win environment for organizations and employees (pp. 111-133). Washington, DC: American Psychological Association.

Bishu, S.G., \& Alkadry, M.G. (2016). A systematic review of the gender pay gap and factors that predict it. Administration and Society, 49(1), 65-104. https://doi. org/10.1177/0095399716636928

Bosch, A. (2015). Reasons for the gender pay gap - What HR practitioners should know. In A. Bosch (Ed.), South African Board for People Practices women's report 2015 (pp. 3-6). Parktown: South African Board for People Practices. Retrieved from http://sabpp.co.za/wp-content/uploads/2015/03/SABPP_Womens-Report-2015_ web.pdf

Boxall, J. (2017). Are SA women not ready for leadership positions? Retrieved from https://www.gsb.uct.ac.za/po-sa-women-not-ready-for-leadership-positions

Burkinshaw, P., \& White, K. (2017). Fixing the women or fixing universities: Women in $\mathrm{HE}$ leadership. Administrative Sciences, 7(30), 1-14. https://doi.org/10.3390/ admsci7030030

Cho, V \& Huang X (2012). Professional commitment, organizational commitment and the intention to leave for professional advancement: An empirical study on IT professionals. Information Technology and People, 25(1), 31-54. https://doi. org/10.1108/09593841211204335

Clark, D. (2007). Why they leave: Reasons executive women flee South African organisations. Retrieved from http://www.leader.co.za/article.aspx?s=6\&f= $1 \& a=245$

Cohen, J.R., Dalton, D.W., Holder-Webb, L.L., \& McMillan, J.J. (2018). An analysis of glass ceiling perceptions in the accounting profession. Journal of Business Ethics, 164, 17-38. https://doi.org/10.1007/s10551-018-4054-4

Cubillo, L., \& Brown, M. (2003). Women into educational leadership and management: International differences? Journal of Educational Administration, 41(3), 278-291. https://doi.org/10.1108/09578230310474421

Das, B.L., \& Baruah, M. (2013). Employee retention: A review of literature. IOSR Journal of Business and Management, 14(2), 8-16. https://doi.org/10.9790/ $487 \mathrm{X}-1420816$

Deery, M. (2008). Talent management, work-life balance and retention strategies. International Journal of Contemporary Hospitality Management, 20(7), 792-806. https://doi.org/10.1108/09596110810897619

Döckel, A. (2003). The effect of retention factors on organisational commitment: An investigation of high technology employees. Unpublished MCom dissertation (Human Resource Management). Pretoria: University of Pretoria.

Döckel, A., Basson, J., \& Coetzee, M. (2006). The effect of retention factors on organisational commitment: An investigation of high technology employees. South African Journal of Human Resource Management, 4(2), 20-28. https://doi. org/10.4102/sajhrm.v4i2.91

Greenhaus, J.H., Ziegert, J.C., \& Allen, T.D. (2012). When family-supportive supervision matters: Relations between multiple sources of support and work-family balance. Journal of Vocational Behaviour, 80(2), 266-275. https://doi.org/10.1016/j. jvb.2011.10.008

Groenewald, J., Odendaal, E., \& Bezuidenhout, A. (2019). Reasons why female audit managers resign from audit firms. Southern African Journal of Accountability and Auditing Research, 21(1), 87-97.

Harcar, T. (2007). Consequences of work-family conflict for working women and possible solutions: A conceptual model. Journal of Global Strategic Management, 2, 60-73.

Hoobler, J., Lemmon, G., \& Wayne, S.J. (2011). Women's underrepresentation in upper management: New insights on a persistent problem. Organizational Dynamics, 40(3), 151-156. https://doi.org/10.1016/j.orgdyn.2011.04.001

Jauhar, J., \& Lau, V. (2018). The 'glass ceiling' and women's career advancement to top management: The moderating effect of social support. Global Business and Management Research: An International Journal, 10(1), 163-178.

Javadi, D., Vega, J., Etienne, C., Wandira, S., Doyle, Y., \& Nishtar, S. (2016). Women who lead: Successes and challenges of five health leaders. Health Systems and Reform, 2(3), 229-240. https://doi.org/10.1080/23288604.2016.1225471
Kalaitzi, S., Czabanowska, K., Fowler-Davis, S., \& Brand, H. (2017). Women leadership barriers in healthcare, academia and business. Equality, Diversity and Inclusion, 36(5), 457-474. https://doi.org/10.1108/EDI-03-2017-0058

Kapareliotis, I., \& Miliopoulou, G. (2019). Gender bias in academia: An attempt to render the intangible tangible. Advanced Series in Management, 22, 247-271. https://doi.org/10.1108/S1877-636120190000022013

Kengne, B.D.S. (2016). Mixed-gender ownership and financial performance of SMEs in South Africa: A multidisciplinary analysis. International Journal of Gender and Entrepreneurship, 8(2), 117-136. https://doi.org/10.1108/IJGE-102014-0040

Kerr-Phillips, B. \& Thomas, A. (2009). Macro and micro challenges for talent retention in South Africa. SA Journal of Human Resource Management, 7(1), 82-91. https:// doi.org/10.4102/sajhrm.v7i1.157

Khalid, S., \& Sekiguchi, T. (2019). The mediating effect of glass ceiling beliefs in the relationship between women's personality traits and their subjective career success. NTU Management Review, 29(3), 193-220.

Kirai, M.N., \& Mukulu, E. (2012). Perceived organisational barriers to women career progression in Kenya's civil service. International Journal of Advances in Management and Economics, 1(6), 203-213.

Kumar, R. (2014). Research methodology: A step-by-step guide for beginners (4th edn.) London: Sage.

Leedy, P., \& Ormrod, J. (2005). Practical research: Planning and design. Pearson, NJ: Pearson Education.

Lekchiri, S., Crowder, C., Schnerre, A., \& Eversole, B.A.W. (2019). Perceived workplace gender-bias and psychological impact. European Journal of Training and Development, 43(3/4), 339-353. https://doi.org/10.1108/EJTD-09-20180088

Lips, H.M. (2013). The gender pay gap: Challenging the rationalizations. Perceived equity, discrimination, and the limits of human capital models. Sex Roles, 68(3) 169-185. https://doi.org/10.1007/s11199-012-0165-z

Mans-Kemp, N. (2019). CEO's exit underscores how few South African women hold top jobs. Retrieved from https://theconversation.com/ceos-exit-underscoreshow-few-south-african-women-hold-top-jobs

Mayer, C., \& May, M. (2018). Of being a container through role definitions: Voices from women leaders in organisational autoethnography. Journal of Organisational Ethnography, 7(3), 373-387. https://doi.org/10.1108/JOE-102017-0052

Ramohai, J. (2019). Women in senior management positions at South African universities: Their movement in, out and across universities. Gender in Management: An International Journal, 34(3), 217-232. https://doi.org/10.1108/ GM-10-2017-0138

Ramohai, J., \& Marumo, K. (2016). Women in senior positions in South Africa education: A reflection on voice and agency. Alternative, 23(1), 135-157.

Ryan, M.K., Haslam, S.A., \& Postmes, T. (2007). Reactions to the glass cliff: Gender differences in the explanations for the precariousness of women's leadership positions. Journal of Organizational Change Management, 20(2), 182-197. https://doi.org/10.1108/09534810710724748

SA Department of Labour. (2016). Commission for employment equity annual report: 2015-2016. Pretoria: Department of Labour. Retrieved from https://www.labour. gov.za/DOL/downloads/documents/annual-reports/employment-equity/20152016/16thCEE Report.pdf

Salinas, P.C., \& Bagni, C. (2017). Gender equality from a European perspective: Myth and reality. Neuron, 96(4), 721-729. https://doi.org/10.1016/j.neuron.2017. 10.002

Scheepers, C.B., Douman, A., \& Moodley, P. (2018). Sponsorship and social identity in advancement of women leaders in South Africa. Gender in Management: in advancement of women leaders in South Africa. Gender in Management: An Internatio

Shepered, S. (2017). Why are there so few female leaders in higher education: A case of structure and agency. Management in Education, 31(2), 82-87. https://doi. org/10.1177/0892020617696631

Statistics South Africa. (2017). Quarterly labour force survey: Quarter 2 - 2017. Pretoria: Stats SA.

Statistics South Africa. (2019). Quarterly labour force survey: Quarter 2 - 2019. Pretoria: Stats SA.

Sweeting, H., Bhaskar, A., Benzeval, M., Propham, F., \& Hunt, K. (2014). Changing gender roles and attitudes and their implications for well-being around the new millennium. Social Psychiatry and Psychiatric Epidemiology, 49(5), 791-809. millennium. Social Psychiatry and Psychiatric
https://doi.org/10.1007/s00127-013-0730-y

Tabassum, N., Shafique, S., Konstantopoulou, A., \& Arslan, A. (2019). Antecedents of women managers' resilience: Conceptual discussion and implications for HRM. International Journal of Organisational Analysis, 27(2), 241-268.

Terre Blanche, M., Durrheim, K., \& Painter, D. (2006). Research in practice Applied methods for the social sciences. Cape Town: University of Cape Town Press.

Thompson, B.M. (2015). Succumbing, surviving, succeeding? Women managers in academia. Gender in Management: An International Journal, 30(5), 397-413. https://doi.org/10.1108/GM-08-2013-0095

Universities South Africa Forum (USAF). (2015). Annual report 2015: New strategic direction. Pretoria: Universities South Africa. 
Vallie, Z. (2018). Are women rising in senior management in SA? Economy. Retrieved from https://www.iol.co.za/business-report/economy/are-women-rising-in-seniormanagement-SA?

Veldsman, T. (2003). Personal communication. Internal Research Report. Midrand: CS Holdings.

Welman, C., Kruger, F., \& Mitchell, B. (2005). Research methodology (3rd edn.). Cape Town: Oxford University Press.
Willows, G., \& Van Der Linde, M. (2016). Women representation on boards: A South African perspective. Meditari Accountancy Research, 24(2), 211-225. https://doi. org/10.1108/MEDAR-01-2016-0001

Zhong, Y., Blum, S.C., \& Couch, S. (2018). Facilitators and constraints: Perceptions of gender differences on women's career advancement. Journal of Tourism and Hospitality Management, 6(2), 61-72. https://doi.org/10.17265/2328-2169/ 2018.04.003 